as outlining the shelf 'edge' beyond which the descent to oceanic depths is relatively abrupt. Rough ground with 'corallines' and coarse deposits prevails in the southern part of the area surveyed, while finer deposits are present farther north, providing better conditions for trawling. The main current affecting the area is the relatively cold Falkland current flowing from south to north, and coldest along its off-shore margin. The warm Brazil current impinges upon this, offshore, in the extreme north-east of the area, where the hydrological conditions may be very complex; but they are normally too far out to affect conditions on the shelf to any important extent. On the inshore flank of the Falkland current (which is a movement of sub-Antarctic surface water) the flow is less strong, so that 'old shelf water' is warmed and sometimes even flows southward as a small intermittent counter-current close in to the land. This seems to have an important effect on the distribution and movements of some of the fishes. The annual cycle of surface temperatures is centred lower than in corresponding latitudes in the northern hemisphere, with the peak after mid-summer, and the annual range is small. At greater depths the temperature range is still smaller and the time-lag between air and sea temperatures is even greater, so that bottom temperatures are highest in autumn and lowest in spring or even early summer.

Some preliminary observations on plankton are discussed, but the large collections obtained have not yet been worked up. The same is true of the benthos. Nevertheless, some fairly firm conclusions have emerged. The general facies of the plankton is closely similar to that found in cold-temperate waters in other parts of the world, but the onset of the main phytoplankton increase falls later in the year than in corresponding latitudes in northern hemispheres, especially towards the outer edge of the shelf. Dependent cycles of higher organisms are therefore also centred later in the year. This in turn affects the largest nekton (fish and squids) in that some at least show a similar 'lateness' in their biological seasons. Species, apparently corresponding to spring spawners elsewhere, spawn about mid-summer in this region, while hake, which in other regions are chiefly-summer spawners, ripen here mainly in autumn.

The second and larger part of the report deals mainly with the demersal fish fauna. It was found that the Patagonian continental shelf is notably poorer in species than are roughly comparable areas elsewhere. Two Merlucciidæ, a true hake (Merluccius hubbsi) and the 'long-tailed hake' (Macruronus magellanicus), were dominant among the larger fishes; and particular attention is devoted to them in the report, which deals in a detailed manner with the relative sizes of Patagonian and European hake, the distribution and relative abundance of Merluccius hubbsi within the area surveyed, the relationship between length and weight of this species and its value as an indicator of the spawning season, food and feeding, and the effect of latitude on numbers, size and sex ratio. Macruronus magellanicus is treated similarly, but slightly less fully, and the main features of the bionomics of the two species are summarized in a very useful table (p. 320).

The principal conclusion of the report is that, although the shelf is not very rich in trawlable fish, hake and some other edible species are present in moderate numbers. Unfortunately, the best trawling grounds are not very near the Falkland Islands.
Nevertheless, the report shows quite clearly that, on the shelf to the northward, roughly equidistant from the Falkland Islands and the lesser Argentine ports, there is a stock of hake just sufficient to enable a modern trawler to pay its way if there were markets equivalent to British ones within a few hundred miles. It is pointed out, however, that the population of the Falkland Islands is too small and too scattered to enable a suitable trawler to pay its way on local trade alone. Whether or not trawling can ever be developed would appear to depend, therefore, upon the growth of a demand for fish at an economic price in the Argentine as well as in the Falklands. Dr. Hart's report shows quite clearly that the raw material for the development of a trawl fishery, at any rate on a small scale, is present on the Patagonian shelf. It is now the task of the administrators and technologists to investigate and assess the prospects of exploiting them.

G. A. STEveN

\section{ASTRONOMICAL OBSERVATIONS IN AUSTRALIA}

$\mathrm{D}^{\mathrm{R}}$ R. R. v. d. R. WOOLLEY, Commonwealth Astronomer of australia, has issued a report covering the period January 1-December 31, 1947, the state of the Observatory at Canberra being represented on the latter date. The report includes the work carried out in fifteen different sections, and the following short summary deals with only a few of the main investigations that are described.

Under solar investigations are included, in addition to a description of the observational work, certain theoretical investigations. Baumbach's estimate of the electronic density in the corona has been recom. puted, allowances having been made for the scattering of the Fraunhofer coronal spectrum by dust and not by electrons, and it appears that the degree of ionization in the corona is caused by collisions with electrons at one million degrees C. In addition, the composition of the corona is shown to be similar to that of other cosmic sources, and the ratio of the number of hydrogen atoms to that of the metals is $6,000: 1$. The collision excitation crosssection of the coronal line has been measured by observation, and the coronal emission in discrete lines, and in continua has been computed. Under astronomical observations are included, among others, the following: the programme of observations of position angle and separation of double stars with the 9 -in. Oddie refractor; work on the determination of the stellar magnitudes of the sun, involving spectro. photometry of the light from a weakened solar image and from Sirius; variable-star investigations for which an electron-multiplier photometer was installed at the Farnham telescope and used to examine the light from several stars known to be spectroscopic variables, but which had not been reported as light variables; monochromatic photometry of brighter stars, using a commercial interference filter which, however, proved unsuitable, as it was transparent outside the nominal transmission band, and hence other methods were tried, as a result of which permanent apparatus for this work is now under construction; and the determination of stellar photometric gradients by using a slitless spectrograph for the Reynolds reflector. In connexion with this last programme, it is pointed out that, as the southern hemisphere is 
about four times as rich as the northerm in bright, early $B$ stars, the determination of accurate gradients and spectral types for these stars should assist materially in the elucidation of the present uncertain colour spectrum relation from $O$ to $B 3$. This is a matter of fundamental importance in studying inter. stellar reddening and galactic structure in general.

Approval has been received for the acquisition of a 74-inch reflector as recommended by the Astronomer Royal when he visited the Observatory in February 1947 , and, while negotiations have been opened with Sir Howard Grubb, Parsons and Co., Ltd., for the construction of an instrument similar to the Radcliffe telescope, a final contract has not yet been arranged. All the smaller mirrors attached to the Observatory have been aluminized by means of the N.R.C. evaporating plant obtained from the Munitions Department, which has also supplied a 42-inch aluminizing tank; this should enable all the existing glass mirrors in the Observatory to be aluminized.

The Ionospheric Prediction Service, which had previously been operated by the Radio Research Board, has been transferred by that body to the Department of the Interior, and attached to the Commonwealth Observatory. It issues two monthly publications-"Radio Propagation Bulletin" and "Tables of Frequency Bands to be used by Ships and Aircraft for Communication with Australian Bases"and also an annual report on long-term forecasting.

\section{MITES AND STORED FOOD PRODUCTS}

$T_{h}^{H}$ HE mites associated with stored food products have received much less attention from biologists than the insect pests found with them. For one thing, students of Acari are few, and mites are often hard to identify. Also, much of the leading systematic writings on these creatures has been published in various languages and in journals that are often very inaccessible. Under the title of "The Mites Associated with Stored Food Products"*, Mrs. A. M. Hughes has written a useful paper that has recently been ssued on behalf of the Ministry of Agriculture and Fisheries. The Department of Scientific and Industrial Research inaugurated a study of the biology of mites, while the Ministry of Food stationed an officer, Mrs. M. Kendall, at the British Museum (Natural History) to study their systematics. She was followed in this work by Mrs. A. M. Hughes, of the Royal Free Hospital School of Medicine, who was deputed to work on a part-time basis, attached to the Infestation Division of the Ministry of Food. This latter Division, it may be added, was transferred to the Ministry of Agriculture and Fisheries in September 1947.

If food be kept in store for any length of time, mites are very liable to infest it and increase to incredible numbers, contaminating it with their excreta and dead bodies. The present publication deals with the mites that affect stored food products, together with the kinds that prey upon them. Also included are certain mites that feed upon small fungi or are parasites on insects or rats. While the biology of many of the mites that are enumerated is unknown, the present descriptive account will serve as a guide

* The Mites Associated with Stored Food Products. By A. M.
Hughes. Pp. 168. (London: H.M. Stationery Office, 1948.) to their identification and, thereby, provide the basis for more extended investigations. The segmentation of the body in mites is peculiarly developed, which makes it difficult to homologize the regions thus demarcated with corresponding areas in other Arthropoda. For this reason, new names are given to the different regions of the body that are displayed in these creatures.

Three sub-orders of mites are recognized, namely, the Sarcoptiformes, Trombidiformes and Parasitiformes. Of the first-named group the Tyroglyphoidea cause the most severe damage. They are small whitish mites occurring in all kinds of stored products when the relative humidity of the immediate environment is 70 per cent or more. Among their members one of the commonest is Glycyphagus domesticus, which not only affects dried food materials but often occurs in enormous numbers in furniture stuffed with untreated Algerian fibre, where it feeds on fungi growing on the fibre. Among the Trombidiformes are many brightly coloured mites, including the familiar 'red spiders'. Some of them are represented in the stored product fauna, where they are predaceous upon other mites or on small insects. The Parasitiformes are highly specialized mites that are divided into the two groups, Ixodides, which do not affect stored products, and the Mesostigmata, which prey upon other mites, insects or small mammals, such as rats and mice.

When collecting mites the use of Oudemans' mix. ture is advised in preference to spirit or formalin. For temporary mounts a 60 per cent solution of lactic acid is satisfactory, while for more permanent preparations a mixture of polyvinol alcohol and lactophenol is better than gum chloral for small species. The composition of these several media is given at the end of the bulletin. There is also a short list of the essential literature dealing with the various groups of mites. The accounts given of the different species are very concise and their value is enhanced by the very numerous figures of structural details.

A. D. Iмms

\section{FORTHCOMING EVENTS}

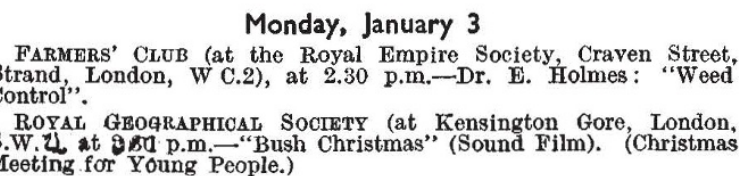

Tuesday, January 4 ROYAL SOCIETy of ARTS (at John Adam Street, Adelphi, London,
W.C.2), at 6 p.m.-Lieut. P. G. Satow : "Radar and its Application to the Science and Art of Marine Navigation".

Wednesday, January 5

SOCIETY OF CHEMICAL INDUSTRY, NUTRITION PANEL OF THE FOOD GRovP (at Gas Industry House, 1 Grosvenor Place, London, S.W.1), at 6.30 p.m.-Discussion on "The Sausage as Food".

INSTITUTE OF WELDING, MANCHESTER AND DISTRIOT BRANCH (in the Reynolds Hall, College of Technology, Manchester), at 7 p.m.Mr. R. R. Sillifant: "Recent Developments in Oxygen Cutting".

\section{Friday, January 7}

Textile Institute, Lancashire Section (at the Textile Institute, 16 St. Mary's Parsonage, Manchester), at 1 p.m.-Mr. L. W. Coxon: "The Philosophy of Management".

SOCIETY of CHEMICAL INDUSTRY, MANCHESTER SECTION (joint meeting with the LOCAL SECTIONS of the CHEMICAI SOCIETY and the ROYAL INSTITUTE OF CHEMrSTRY, at the Engineers' Club, Albert Square, Manchester), at 6.45 p.m.--Dr. H. Steiner: "Production of Acetylene from Hydrocarbons;"

PAPER Makers' Association, TeChNiCAL SECTION, NORTHERN DIVISION (at the Engineers' Club, Albert Square, Manchester), at 7 p.m. $\rightarrow$ Mr. H. R. Hutley : "The Technical Education of Juveniles in the Paper Industry-Practical Considerations". 